\title{
INCLUSÃO SOCIAL NO CONTEXTO POLÍTICO DA BIOÉTICA
}

\section{Social inclusion in the political context of bioethics}

\author{
Volnei Garrafa \\ Cátedra UNESCO de Bioética da Universidade de Brasília, Brasília, Distrito Federal, \\ Brasil. \\ volnei@unb.br
}

Resumo: O presente artigo reforça a necessidade de politização da bioética como forma de construção da justiça social. Analisa a inclusão social a partir dos conceitos de empoderamento, libertação e emancipação, como possíveis ferramentas epistemológicas da Bioética de Intervenção. Além das características relacionadas ao rigor acadêmico, o texto defende a necessidade da ação política concreta para a transformação social. Apresenta o teor da Declaração Universal de Bioética e Direitos Humanos construída pela UNESCO com a participação efetiva dos países em desenvolvimento, discutindo o avanço representado pela incorporação dos temas sociais e ambientais à agenda da bioética do século XXI.

Palavras-chave: Bioética de Intervenção. Bioética e política. Empoderamento. Libertação. Emancipação. Direitos Humanos.

\begin{abstract}
This article reinforces the need of a politics-oriented bioethics as an instrument to build social justice. It analyzes social inclusion from some concepts such as empowerment, liberation and emancipation, as they are the epistemological tools of Intervention Bioethics. The text defends the necessity of a concrete political action aiming at social transformation. It presents the content of the Universal Draft Declaration on Bioethics and Human Rights assembled by UNESCO with the effective participation of developing countries, discussing the advance attained by the inclusion of social and environmental themes to the bioethics agenda of $21^{\text {st }}$ century.
\end{abstract}

Key words: Intervention Bioethics. Bioethics and politics. Empowerment. Liberation. Emancipation. Human Rights. 
Nos

os países latino-americanos, de modo geral, e no Brasil, especificamente, o tema da justiça sanitária faz parte da agenda bioética. As imensas desigualdades no acesso aos recursos - a tudo que caracteriza a qualidade de vida - tornam esse tema efetivamente orgânico quando se pretende aplicar a ética para garantir a dignidade da vida humana. Isso não significa que em outras regiões do mundo o assunto seja aceito pacificamente. Pelo contrário, em alguns países desenvolvidos e mesmo em determinados núcleos acadêmicos das nações em desenvolvimento, existem fortes resistências à utilização, no campo sanitário, dos paradigmas referenciais da bioética, que se volta preferencialmente à biotecnologia e, com a mesma ênfase, recusa a politização da pauta bioética internacional.

Duas são as razões básicas para essa resistência. Em primeiro lugar, o preciosismo acadêmico de alguns estudiosos da área que, utilizando a lógica formal e assépticas argumentações teóricas, tentam desqualificar o academicismo do debate sócio-político da bioética, afirmando que a temática política, que inclui temas da saúde pública e coletiva, como a inclusão social e outros, está fora do escopo epistemológico da disciplina, constituindo na realidade outra área, que denominam de "biopolítica" (KOTTOW, 2005).

Em relação a essa primeira razão, pode-se questionar o sentido intrínseco de tal posicionamento. Como aponta Castoriadis, o filósofo foi, desde o início da civilização grega, um cidadão plenamente inserido no seio da sociedade da qual fazia parte, a polis, atuando como tal na vida social, a exemplo de Sócrates. Dessa forma, a filosofia se dedicava a questionar a ordem estabelecida, em lugar de meramente justificar sua reprodução por meio de fórmulas que se descolam da realidade concreta, experimentada cotidianamente.

Desde Platão e, de maneira crescente em Kant e outros filósofos modernos, a dissociação entre a razão e a ação vem provocando um tipo de "perversidade edificante" que privilegia a primeira em detrimento da segunda. Tal tendência, que na pós-modernidade ganhou contornos de niilismo estagnado, impede tanto a reflexão quanto a ação - o processo dialético - que hoje é indispensável na medida em que a tecnociência institui novas fronteiras para o exercício do poder. Esse limite não se restringe apenas ao adestramento da corporeidade pelo desempenho "autônomo" das regras e normas sociais, como sempre aconteceu. Pela ação da tecnologia, o controle social imiscui-se nesse mesmo corpo e recria-o a partir de uma linha divisória que secciona inexoravelmente aqueles que têm direito à qualidade de vida e bem-estar, dos demais que, privados disso, são cerceados à condição de sustentáculos da desigualdade. 
Nesse sentido, cabe um reparo à idéia de transformar o princípio justo da proteção em uma epistemologia de cunho mais abrangente como forma de suprimir as desigualdades. Ainda que proteger os que suportam a ordem estabelecida, a custa da expropriação de seus corpos e vidas, e defender sua integridade frente aos que usufruem todos os benefícios dessa divisão espúria seja uma ação que pode melhorar sua qualidade de vida, restringir a possibilidade de intervir na realidade à proteção aos menos favorecidos não deixa de ser uma concessão com a manutenção da desigualdade, dos privilégios e da exclusão. Por isso, deve-se considerar a proteção como um princípio, essencial para a construção da justiça social, mas que não deve ser alçado à condição de matriz teórica.

Sob a capa de um humanismo paternalista e patriarcal a maximização do princípio da proteção acaba revelando, em última análise, a assimetria concreta entre quem protege e quem é protegido. De certa forma, revela também uma admiração acrítica pelo pensamento escolástico, mesmo quando este somente reproduz uma retórica esvaziada do sentido que deve impregnar a relação entre teoria e prática, entre o plano ideal e a realidade. Com relação a isso, Castoriadis afirma que:

"só sairemos da perversão que caracterizou o papel dos intelectuais desde Platão, e de novo agora nos últimos setenta anos, se o intelectual se tornar verdadeiramente cidadão. Um cidadão não é (não é necessariamente) 'militante de um partido', mas alguém que reivindica ativamente sua participação na vida pública e nos negócios comuns, tanto quanto os outros. Aqui aparece com toda a evidência uma antinomia, que não tem solução teórica, que somente a phronésis, a sabedoria, pode permitir ultrapassar. O intelectual deve pretender ser cidadão como os outros, deve também pretender ser, de direito, porta-voz da universalidade e da objetividade. O intelectual só pode se manter nesse espaço, reconhecendo os limites do que sua suposta objetividade e universalidade lhe permitem. Deve reconhecer, e não com desdém, que o que ele tenta fazer entender é ainda uma doxa, uma opinião, e não uma epistémé. Cumpre sobretudo reconhecer que a história é o domínio onde se desenvolve a criatividade de todos, homens e mulheres, eruditos e analfabetos, de uma humanidade na qual ele mesmo é apenas um átomo. E isso ainda não deve vir a ser pretexto para que se afiance, sem crítica, as decisões da maioria, nem para que se incline diante da força, por ser ela a expressão dos mais numerosos" (CASTORIADIS, 1992). 
Em segundo lugar, e talvez, como decorrência lógica dessa primeira posição, tal resistência pode ser imputada ao conservadorismo ou estreiteza política de certos pesquisadores, que acreditam que toda gama de conflitos éticos relacionados à vida e à saúde pode ser circunscrita ao âmbito biomédico, mesmo com certas inclusões tangenciais de alguns deles pelo campo social. Sob tal argumento, criticam as tentativas de transportar essa discussão para o campo onde verdadeiramente se dão as grandes decisões, que alijam ou incluem indivíduos como beneficiários do desenvolvimento científico e tecnológico, ou seja, a seara das decisões políticas.

Disfarçados sob as vestes do vazio ideológico deixado pela modernidade tardia (ou pós-modernidade, se preferirem os leitores...) e, com outra linguagem, ressuscitam uma superada contradição fortemente constatada na América Latina dos anos 1960 e 1970. Naqueles tempos, notáveis sanitaristas como os saudosos Juan Cesar Garcia, Cecília Donângelo e Sergio Arouca, entre tantos outros que ainda seguem vivos nas mesmas trincheiras, tiveram que empreender heróica resistência às ditaduras militares plantadas no continente. Nas suas áreas de trabalho, combateram e transformaram os estreitos referenciais da antiga medicina social e os conteúdos preventivistas em moda na época, por meio da construção concreta de pautas socialmente comprometidas com a essência democrática e inclusiva da saúde pública e coletiva.

A bioética social, para ser efetiva, além de disposição, persistência e preparo acadêmico, exige uma espécie de militância programática e coerência histórica por parte do pesquisador. De minha parte, é o que venho tentando fazer há alguns anos com a linha de pesquisa que denominei inicialmente de Bioética Dura (hard bioethics) e posteriormente Bioética de Intervenção (GARRAFA, 2000; GARRAFA \& PORTO, 2003). A Encyclopedia of Bioethics, no capítulo dedicado à América Latina, em sua última edição, traz comentários positivos do responsável pela matéria, prof. José Alberto Mainetti, sobre o surgimento da Bioética Dura na região.

Com vistas a aprofundar os fundamentos epistemológicos dessa vertente latino-americana da bioética, analiso neste artigo o tema da justiça social em saúde e sua relação com a bioética, a partir dos diferentes conceitos utilizados para promover inclusão social e a expansão significativa que o assunto adquiriu com sua inserção na Declaração Universal de Bioética e Direitos Humanos, a ser homologada pela UNESCO em outubro de 2005, na sua Assembléia anual. Neste sentido, após a consagração da Declaração, com o considerável avanço logrado no conteúdo referido ao campo social, pretendo passar a incorporar a 
Bioética de Intervenção, definitivamente, à "Bioética Social", uma vez que já terá sido alcançado um dos principais motivos de sua criação, ou seja, a necessária visibilidade política ao tema.

\section{Discutindo a Inclusão Social na Epistemologia da Bioética}

O tema da inclusão social recebeu suporte teórico de diversos conceitos cunhados no campo da saúde pública nos últimos anos. Algumas destas palavras revelaram-se bastante apropriadas, outras nem tanto... No campo da bioética, igualmente, diferentes autores têm tratado o assunto sob ângulos e interpretações diversas. Tão importante quanto o significado da expressão escolhida, naturalmente, são as justificativas e a sustentação argumentativa com relação a sua utilização. Para o objetivo dessa discussão, analiso três expressões recorrentes - empoderamento, libertação e emancipação - que podem embasar o debate sobre quais princípios se prestam a sustentar a intervenção bioética no campo social.

A palavra empoderamento, tradução livre e direta do inglês, teve seu uso fortalecido a partir do momento em que o cientista indiano Amartya Sen, recebeu o Prêmio Nobel de Economia. Sem dúvida, em nosso idioma, esta versão cunhou uma palavra feia, de difícil pronúncia e audição, mas que, não obstante, possui um apelo prático especialmente grande. De qualquer modo, justiça seja feita, ao longo de toda sua vasta obra, para dar idéia de empoderamento, Sen utiliza com freqüência a palavra liberdade, como na seguinte passagem: "Para que se torne possível superar a fome, a pobreza, as ameaças de destruição do meio ambiente e outras formas de iniqüidade, exige-se da sociedade uma postura de cumplicidade fortalecedora da idéia de liberdade, da qual ela mesma não pode se furtar" (SEN, 2000).

Tal como apontado neste trecho, a idéia de empoderamento dos sujeitos individuais, vulnerabilizados em decorrência do processo histórico e da característica cultural das sociedades nas quais estão inseridos, perpassa o todo social, atuando como elemento capaz de amplificar as vozes dos segmentos alijados do poder de decisão, e promovendo sua inserção social. A idéia do empoderamento estaria, portanto, alicerçada na articulação orgânica entre os diferentes grupos e segmentos, processo que, como já apontava Durkheim, é o que transforma um mero aglomerado de indivíduos em uma sociedade (DURKHEIM, 1990). 
A meu ver, o que confere humanidade aos seres biologicamente reconhecidos como humanos, decorre de um processo coletivo, que se consubstancia na produção e reprodução contínuas dos significados atribuídos às práticas sociais. Neste sentido, a proposta inclusiva aqui desenvolvida passa pelo pressuposto que a ação social politicamente comprometida é aquela capaz de transformar a práxis social.

Essa definição coaduna-se aos marcos teóricos delineados pela Bioética de Intervenção, que aponta o corpo como parâmetro da intervenção ética (GARRAFA \& PORTO, Op. Cit.). Ela identifica e incorpora a dimensão social, a percepção da pessoa como uma totalidade somática na qual estão articuladas as dimensões física e psíquica, que se manifestam de maneira integrada nas inter-relações sociais e nas relações com o meio. Nesse sentido, a visão de empoderamento delineada por Sen estabelece a ponte entre os indivíduos, cuja corporeidade sustenta o processo de produção e reprodução social e a coletividade da qual essas pessoas fazem parte. Explicita-se, assim, a relação dialética entre reflexão e ação na responsabilidade individual e coletiva pelo impacto que as escolhas dos indivíduos produzem na realidade.

Assim, parece claro que a idéia de empoderamento reporta justamente à importância de perceber que as escolhas dos sujeitos sociais não podem ser marcadas apenas por uma visão míope e estereotipada de autonomia, que circunscreve a opção individual ao exercício narcísico e antropocêntrico, levando o pensamento em direção à questão do poder de uns e outros cidadãos em mundos desiguais. E se a desigualdade é construída no meio social - na formação do indivíduo - suplantá-la implica em reconhecer a relação inequívoca entre autonomia e responsabilidade. A autonomia se manifesta não só na capacidade de responder a uma situação de forma a atender ao mesmo tempo à moralidade social, às normas legais, aos desejos, necessidades e vontades do indivíduo, como também no reconhecimento da interconexão entre os seres humanos e todas as formas de vida, assim como na responsabilidade existencial exigida frente a elas.

Em abril de 2004, proferi a conferência de encerramento do V Congresso Brasileiro de Bioética, realizado em Recife cujo tema foi "A bioética no século XXI". Tendo, como de costume, levado a discussão para o âmbito social e da politização da bioética, comparei as idéias de Sen e a também extraordinária produção do educador brasileiro Paulo Freire. Guardadas as peculiaridades de cada palavra e de cada contexto, Sen de certa forma expressa com o uso da categoria empoderamento o que Freire denomina libertação. 
Porém, a idéia de libertação implica em mais do que o simples reconhecimento da existência do poder. Ela, necessariamente, aponta para o locus aonde se instalam a força capaz de obrigar à sujeição, e a fragilidade, manifesta na incapacidade de desvencilhar-se da submissão. Ao definir esses pólos, Freire identifica a oposição entre cativeiro, ou a privação do direito de escolha, e a libertação, o verdadeiro exercício da autonomia. Dessa forma, assinala que os sujeitos sociais são, eminentemente, atores políticos, cuja ação pode tanto manter como transformar o status quo. A categoria libertação desvela as posições de poder e permite pressupor uma tomada de posição no jogo de forças pela inclusão social.

A utilização desta categoria na Bioética de Intervenção pretende apontar em que direção se deve conduzir a luta política para garantir tal liberdade. Sua adoção visibiliza a luta das cidadãs e cidadãos que logram sua inclusão social, seja no contexto da saúde ou em contextos mais amplos, a partir da tomada de consciência sobre as forças que os oprimem e pela ação concreta em oposição a elas. Paulo Freire é particularmente contundente ao criticar o preciosismo acadêmico e sua malvada conseqüência, a assepsia moral, que constituem obstáculos à libertação:

"Daí o tom de raiva, legítima raiva, que envolve o meu discurso quando me refiro às injustiças a que são submetidos os esfarrapados do mundo. Daí o meu nenhum interesse de, não importa que ordem, assumir um ar de observador imparcial, objetivo, seguro, dos fatos e dos acontecimentos. Em tempo algum pude ser um observador 'acinzentadamente' imparcial, o que, porém, jamais me afastou de uma posição rigorosamente ética. Quem observa o faz de um certo ponto de vista, o que não situa o observador em erro. O erro na verdade não é ter um certo ponto de vista, mas absolutizá-lo e desconhecer que, mesmo do acerto de seu ponto de vista é possível que a razão ética nem sempre esteja com ele. O meu ponto de vista é o dos 'condenados da Terra', o dos excluídos" (FREIRE, 2001).

No entanto, o que se vê no meio da saúde pública brasileira é que a palavra empoderamento tem uma utilização bastante aceita e incorporada ao nosso léxico sanitário, enquanto libertação é raramente utilizada. Entre outras razões, imputo essa constatação ao fato de Sen trabalhar na área de economia, de grande visibilidade no contexto capitalista contemporâneo, ao passo que Freire se debatia em meio a teorias educacionais, de menor apelo mercadológico, trabalhando a idéia da educação como prática de libertação. 
Embora os dois autores tenham desenvolvido seus estudos no sentido de favorecer as populações dos países pobres do Hemisfério Sul do mundo, o apelo da economia, infelizmente, é flagrantemente maior que o da educação, no atual contexto histórico pelo qual passa a humanidade.

A terceira expressão que incluo nessa análise é emancipação. O sujeito emancipado não deixa de ser um sujeito livre. O jovem emancipado, por exemplo, é aquele que adquiriu status de maioridade e passa a ser senhor e responsável pelos seus próprios atos. Emancipação significa alforria, independência, liberdade, o caminhar que se inicia com a libertação. Só é emancipado aquele que suprimiu sua dependência, que alcançou o domínio sobre si mesmo e pode garantir não apenas a sobrevivência, mas suas escolhas frente aos meios de alcançar essa sobrevivência. O poder sobre si mesmo é o que outorga a emancipação, tornando a pessoa imune às forças que buscam sua sujeição. Portanto, suprimir a dependência é pré-condição para a emancipação, e isso vale tanto para a pessoa quanto para o Estado. É nessa concepção que a categoria emancipação se presta à Bioética de Intervenção como ferramenta ou veículo para direcionar a luta pela libertação e para colocar essa luta na dimensão coletiva.

No entanto, parece-me que, pelo menos ao ouvido, a emancipação tem um sentido mais jurídico do que político, sublinhando o reconhecimento legal da capacidade de decidir. Porém, para que a inclusão social (inerente ao cidadão emancipado) reflita efetivamente sua autonomia, ela deve ser fruto de uma conquista pelo direito de decidir e pela possibilidade real do exercício desse direito, não podendo decorrer de mera concessão, como um presente que sem luta foi ofertado e que, por isso, da mesma forma, pode ser tirado ao sabor da vontade de quem concedeu a dádiva, como ocorre no caso da proteção.

Para a Bioética de Intervenção, a inclusão social é a ação cotidiana de pessoas concretas e precisa ser tomada na dimensão política, como um processo no qual os sujeitos sociais articulam sua ação. Na medida em que a ação cotidiana direciona as escolhas não apenas em função de uma inclinação pessoal, mas considerando a dimensão do todo - a necessidade de garantir a existência das pessoas e de todas as formas de vida - ela se torna inclusiva, tendendo, como decorrência, à maior simetria.

De qualquer modo, creio que qualquer uma das três expressões empoderamento, libertação e emancipação - embora com conotações diferentes, auxiliam à compreensão do fenômeno de inclusão social como um processo dinâmico que necessita ser construído e levado à prática, objetivando a conquista da verdadeira justiça social em saúde. 


\section{A Agenda Social na Declaração Universal de Bioética e Direitos Humanos}

Depois de mais de dois anos de intensas discussões e a produção de consecutivas versões, entre os dias 20 e 24 de junho de 2005, foi realizada na UNESCO, em Paris, a reunião definitiva de experts dos diversos governos filiados àquela Organização, com o objetivo de definir o teor da futura Declaração Universal de Bioética e Direitos Humanos. Após a superação de inúmeras dificuldades, tendo em vista posições antagônicas de diferentes países sobre as mesmas questões, finalmente chegou-se a um documento consensual.

Desde o início das negociações, ficou patente o interesse dos países ricos e seus satélites, guiados por Estados Unidos, Alemanha e Canadá, em reduzir a agenda bioética aos temas relacionados exclusivamente à biotecnologia/biomedicina, alijando sumariamente os outros dois pilares da disciplina, caros aos países em desenvolvimento do Hemisfério Sul: a bioética social e a bioética ambiental. A delegação brasileira teve um papel político fundamental na condução da reação dos países periféricos, com o apoio das nações latino-americanas - muito especialmente da Argentina - africanas, de alguns países árabes e da Índia.

Embora se saiba que uma Declaração Internacional deste tipo contenha apenas normas não vinculantes, que não podem ser consideradas como lei, servem como guias futuros para a construção das legislações nos diferentes Estados. Neste sentido, o documento construído em Paris pode ser considerado um avanço extraordinário para os países em desenvolvimento. Sua construção mostra um preâmbulo substancial composto de vários considerandos, onde são mencionados como referência documentos e tratados internacionais já aprovados pelas Nações Unidas. Posteriormente, vem a Declaração propriamente dita, com 28 artigos, divididos em cinco capítulos: um capítulo introdutório com as disposições gerais que incluem o escopo e objetivos da bioética (dois artigos), seguido de outros dois que trazem os princípios (em número de 15) e sua aplicação (quatro artigos), além de duas partes finais relativas a sua implementação e promoção (quatro artigos), finalizando com as considerações finais (três artigos).

O mais importante, para os objetivos deste texto, se refere às conquistas obtidas na Declaração com relação ao campo da saúde pública e da inclusão social. Entre outros, foram incluídos tópicos sobre dignidade humana e direitos humanos; respeito pela vulnerabilidade humana e integridade pessoal; 
igualdade, justiça e eqüidade; respeito pela diversidade cultural e pluralismo; solidariedade e cooperação; proteção do meio ambiente, biosfera e biodiversidade; responsabilidade social e saúde pública e divisão dos benefícios. Em relação a esses dois últimos pontos ficou claro o compromisso dos Estados-membro em proporcionar acesso a sistemas sanitários de qualidade, aos benefícios do desenvolvimento científico e tecnológico, a novos medicamentos e à nutrição, assim como à redução da pobreza e outros temas afins, tão caros à pauta contemporânea da saúde pública.

Além disso, deve ser mencionada a inclusão de um tópico que poderá servir de antídoto contra o avanço da teoria do duplo-standard nas pesquisas em países pobres e ricos, embora se tenha conseguido colocá-lo apenas no preâmbulo do documento: “... os seres humanos, sem distinção, deveriam ser beneficiados pelos mesmos elevados padrões éticos nas pesquisas em medicina e nas ciências da vida" (UNESCO, 2005).

De modo geral, portanto, a Declaração Universal de Bioética e Direitos Humanos re-define a agenda bioética para o século XXI, expandindo generosamente seu campo de interpretação, pesquisa e ação. As firmes e legítimas ações políticas dos países latino-americanos foram decisivas para a mudança do panorama. Ou seja: a Bioética incursionou pela política para incluir as questões sociais em sua agenda. E isso não é biopolítica. É a bioética intervindo em uma dimensão mais ampla: a política. Esse grande passo trará, sem dúvida, conseqüências positivas e concretas no sentido de ampliar as discussões éticas em saúde, proporcionar melhores condições para implementação de medidas de inclusão social e favorecer a construção de sistemas sanitários mais acessíveis; criando, assim, condição para que as sociedades humanas alcancem uma qualidade de vida mais justa.

Para a Bioética de Intervenção, o reconhecimento dessas pautas teve distintos significados. A inclusão de tais temáticas no contexto das Nações Unidas reafirmou a relevância de seus pressupostos teóricos, legitimando a pertinência da intervenção ético-política nesse âmbito. Por outro lado, consubstanciou uma ação efetiva de intervenção no sentido de conformar a realidade a partir de parâmetros de eqüidade, inclusão social e justiça. Mais do que isso, porém, a criação desse documento traçou uma orientação universal e objetiva a partir da qual a bioética pode lutar pelo empoderamento, pela libertação e pela emancipação dos "condenados da terra".

Agradecimento: Agradeço a Dora Porto, companheira de primeira hora na construção da Bioética de Intervenção, pelas preciosas sugestões ao presente texto, bem como pela parceria constante nas reflexões sobre o tema. 


\section{Referências Bibliográficas}

CASTORIADIS, C. O mundo fragmentado: as encruzilhadas do labirinto / 3. São Paulo, Paz e Terra, 1992.

DURKHEIM, É. As regras do método sociológico. São Paulo, Companhia Editora Nacional, 1990.

FREIRE, P. Pedagogia da Autonomia. São Paulo, Paz e Terra, 2001.

GARRAFA, V. Bioética fuerte - uma perspectiva periférica a las teorias bioéticas tradicionales. Conferência. Congreso de la Federación Latino-Americana y del Caribe de Instituciones de Bioetica, Panamá, 2000. mimeo.

GARRAFA, V. \& PORTO, D. Intervention bioethics: a proposal for peripheral countries in a context of power and injustice: Bioethics. 17 (5-6):399-416, 2003.

KOTTOW, M. Bioética y biopolítica. Revista Brasileira de Bioética, 1 (2): 110-121, 2005.

POST, S.G., [Ed.] Encyclopedia of bioethics. $3^{\text {rd }}$ edition. New York, Macmillan Publisher Company, 2003.

SEN, A. Desenvolvimento como liberdade. São Paulo, Companhia das Letras, 2000.

UNESCO. Universal Draft Declaration on Bioethics and Human Rights. Paris, mimeo, 24 de junho 2005. 